\title{
Clean Energy, Australian Electricity Markets, and Information Transmission
}

\author{
Sitara Karim ${ }^{1}$ (D), Muhammad Abubakr Naeem ${ }^{2}$ (D) $^{\text {a }}$ \\ ${ }^{1}$ Department of Business Administration, ILMA University, Pakistan, 2 Smurfit Graduate School of Business, University College Dublin, Ireland \\ Keywords: clean energy, JEL G00 K32 194, Australian energy markets, TVP-VAR \\ https://doi.org/10.46557/001c.29973
}

Energy RESEARCH LETTERS

Vol. 3, Issue 3, 2022

This study investigates the connectedness between the clean energy and Australian electricity markets from May 2005 to December 2020. Using time-varying parameter vector autoregressions, we find weak connectedness between the clean energy and Australian electricity markets. The weak connectedness of the clean energy markets to the electricity markets illustrates the diversification potential of clean energy for Australian electricity markets. We cite several implications for policymakers, regulatory bodies, investors, and market participants.

\section{Introduction}

The rapid expansion of sustainable development and clean energy market has increased the interest of both scholars and practitioners (Taghizadeh-Hesary \& Yoshino, 2019). The sharp boost in the clean energy market and its substantial impact on overall financial markets has attracted the attention of investors and policymakers. Investors are now attracted to clean and green energy investments that offer significant diversification potential and a moderate level of risk, to avoid financial losses during volatile times. Earlier empirical studies (e.g., Albulescu et al., 2020; Elsayed et al., 2020; Liu \& Hamori, 2021) have investigated the prospective benefits of the clean energy market through various methodologies, with unequivocal outcomes. In addition, the challenges of businesses acquiring renewable and clean energy resources have remained considerable among regulators, financial market participants, and policymakers.

Among regulators, the Australian Energy Market Operator is currently operating six national electricity markets in Australia. The Australian economy's heavy reliance upon fossil fuels and nonrenewable energy sources has raised the dual concerns of insufficient supply and climate change. Musa et al. (2018) document that the world's oil and gas reserves will be depleted by the middle of this century, with coal reserves projected to be drained 60 years later. Transitioning from nonrenewables to renewables and clean energy sources has been a focus for the Australian Energy Market Operator (Do et al., 2020). Carbon policy is an attempt to achieve the goal of transitioning from fossil fuel to lower-carbon electricity production (Apergis et al., 2020). Li et al. (2020) report that Australia's total energy consump- tion from renewables is only $6 \%$, with $86.3 \%$ of the country's electricity generated from fossil fuels.

Against this background, this study strives to examine the connectedness between clean energy and five Australian electricity markets from May 2005 to December 2020, using time-varying parameter vector autoregression (TVP-VAR). TVP-VAR techniques provide two benefits. First, they reveal the markets' system-wide net connectedness; second, they specify time-varying characteristics to assess the potential impact of financial contagion on the overall system of markets. This study contributes to this literature strand by measuring the connectedness between the clean energy and Australian electricity markets using a TVP-VAR model and offers meaningful implications for policymakers, regulators, and investors. We find weaker connectedness between the clean energy and Australian electricity markets, where Victoria and New South Wales (NSW) are net contributors of spillovers, while Queensland (QLD), Tasmania (TAS), and South Australia (SA) are net recipients. The pairwise connectedness of the clean energy market with electricity markets proposes that the inclusion of this investment tool in portfolios has considerable diversification potential for investors, to minimize risk during uncertain economic conditions.

The remainder of the paper proceeds as follows. Section II presents the data and empirical methods. Section III elaborates upon the empirical results. Finally, Section IV concludes the paper with policy recommendations. 
Table 1. Descriptive statistics

\begin{tabular}{l|cccccc}
\hline & SPCL & NSW & QLD & SA & TAS & VIC \\
\hline Mean & -0.004 & 0.082 & 0.018 & -0.037 & -0.103 & 0.068 \\
Median & 0.052 & -0.412 & -0.506 & -0.051 & -0.059 & -0.233 \\
Maximum & 18.093 & 406.415 & 404.539 & 439.786 & 421.499 & 591.573 \\
Minimum & -14.973 & -403.291 & -414.325 & -622.624 & -368.362 & -530.013 \\
Std. Dev. & 1.748 & 32.794 & 37.679 & 52.404 & 33.665 & 34.955 \\
Skewness & -0.563 & -0.338 & -0.168 & -0.075 & -0.160 & 0.377 \\
Kurtosis & 16.193 & 46.678 & 30.969 & 22.239 & 28.295 & 47.751 \\
Jarque-Bera & $40803.69 \mathrm{a}$ & $444144.7^{\mathrm{a}}$ & $182102.4^{\mathrm{a}}$ & $86152.37^{\mathrm{a}}$ & $148950.8^{\mathrm{a}}$ & $466247.8^{\mathrm{a}}$ \\
Corr_SPCL & 1.000 & 0.008 & 0.003 & 0.020 & -0.002 & 0.015 \\
Observations & 5586 & 5586 & 5586 & 5586 & 5586 & 5586 \\
\hline
\end{tabular}

This table shows the descriptive statistics. Note that "a" indicates significance at $1 \%$.

\section{Data and empirical methods A. Data and preliminary statistics}

To examine the time-varying parameters of the clean energy and Australian electricity markets, we utilize data from May 2005 to December 2020 on Standard \& Poor's Clean Energy (SPCL), sourced from Datastream, and five Australian national electricity markets, namely, NSW, QLD, SA, TAS, and Victoria (VIC), obtained from the National Electricity Market website. For estimation purposes, the daily prices of electricity markets are converted to log-differenced returns. Table 1 presents descriptive statistics of the clean energy and Australian electricity markets where NSW and VIC show the highest mean values and QLD shows a modest average value. Alternatively, SA, TAS, and SPCL exhibit negative average values. The greatest variability in returns is observed for SA, followed by QLD, VIC, TAS, and NSW. Meanwhile, SPCL reports the least volatility in average returns. The Jarque-Bera test reveals abnormal values indicating that the markets are not normally distributed and have asymmetric characteristics. Further, the correlation analysis of SPCL with electricity markets exhibits the highest correlation with SA, followed by VIC, whereas the lowest correlations are observed for NSW, QLD, and TAS.

\section{B. Empirical method}

To examine the connectedness between the clean energy and Australian electricity markets, we use the TVP-VAR model of Primiceri (2005), which was later extended by Antonakakis \& Gabauer (2017). This model determines the possible changes in the connectedness of the markets to demonstrate whether the linear structure is derived from the probability of the shocks or from the extension of the change mechanism (response). The model also has the unique ability to identify potential structural breaks and substantially explains the relations among the variables. The model is stated as follows:

$$
\begin{aligned}
y_{t}= & \beta_{0, t}+\beta_{1, t} y_{t-1}+\ldots \\
& +\beta_{p, t} y_{t-p}+u_{t}+X_{t}^{\prime} \Theta_{t}+u_{t}, \\
& X_{t}^{\prime}=\left[1, y_{t-1}^{\prime}, \ldots, y_{t-p}^{\prime}\right]
\end{aligned}
$$

where $y_{t}$ is an $n \times 1$ vector for the dependent variable, $\beta_{0, t} \cdots p, t$ denotes $n \times n$ time-varying coefficients that are rewritten as the $\Theta_{t}$ matrix, $X_{t}$ represents an $n \times k$ matrix comprising the intercepts and lags of the time-dependent variables, and $u_{t}$ denotes structural shocks with an $n \times 1$ heteroskedastic distribution term with a zero mean and a time-varying variance-covariance matrix $\Omega_{t}$. Given the logdifferenced returns of SPCL and the electricity markets, the variance-covariance matrix is segregated as

$$
\Omega_{t}=M_{t}^{-1} H_{t}\left(M_{t}^{-1}\right)
$$

where $M_{t}^{-1}$ shows the simultaneous relations between the variables and $H_{t}$ represents stochastic connectedness. Moreover, the transitions in the time-varying parameters are observed to be as follows:

$$
\begin{gathered}
\Theta_{t}=\Theta_{t-1}+v_{t}, \\
v_{t} \approx N(0, S) \\
\alpha_{t}=\alpha_{t-1}+\xi_{t}, \\
\xi_{t} \approx N(0, Q) \\
\ln h_{i, t}=\ln h_{i t-1}+\sigma_{i} \eta_{i, t}, \\
\eta_{i, t} \approx N(0,1)
\end{gathered}
$$

where Eqs. (4) and (5) estimate the time-varying parameters following a random walk process and Eq. (6) examines stochastic connectedness following the independent random walk. Primiceri (2005) proposes that the coefficients among the variables change independently, to simplify the inference and increase the efficiency of the estimates. The main equation error term is thus determined to be independent of the transition equation.

\section{Empirical results}

Table 2 presents the connectedness of the clean energy and Australian electricity markets from May 2005 to December 2020, where system-wide connectedness is reported at $31.20 \%$, with VIC and NSW as the net transmitters of spillovers. Conversely, TAS, QLD, SPCL, and SA are the net recipients of spillovers. The strong connectedness of VIC and NSW reveals their maximum electricity generation capacity and the closer geographical locations of both markets. In line with Yan \& Trück (2020), Han et al. (2020), and Apergis et al. (2020), the physical interconnectors, geographical proximity, and highest electricity generation ca- 
Table 2. Connectedness Table

\begin{tabular}{l|cccccc|c}
\hline & SPCL & NSW & QLD & SA & TAS & VIC & FROM \\
\hline SPCL & 94.4 & 1 & 1.3 & 0.9 & 1.2 & 1 & 5.6 \\
NSW & 0.5 & 56.9 & 16.4 & 8 & 3.3 & 14.9 & 43.1 \\
QLD & 0.7 & 18.8 & 68.9 & 3.6 & 1.9 & 6.1 & 31.1 \\
SA & 0.5 & 7.7 & 3 & 60.2 & 4.2 & 24.3 & 39.8 \\
TAS & 1 & 4.4 & 2 & 5.6 & 78.1 & 8.9 & 21.9 \\
VIC & 0.5 & 12.9 & 4.8 & 21.7 & 6.1 & 54 & 46 \\
\hline Contribution TO others & 3.3 & 44.9 & 27.7 & 39.7 & 16.8 & 55.2 & 187.5 \\
\hline NET directional connectedness & -2.3 & 1.8 & -3.4 & -0.1 & -5.1 & 9.2 & TCl = 31.20\% \\
\hline
\end{tabular}

pacity of these markets result in the formation of strong spillover to other markets. Moreover, the negative values of net connectedness point to the power generation capacity of the respective electricity markets, as contended by Apergis et al. (2020), where juvenile electricity markets are the least connected within a system. The weakest connectedness of SPCL to the electricity markets highlights its diversification potential for the electricity markets of Australia. Consistent with the work of Elsayed et al. (2020), SPCL mainly receives the spillover from various energy and global financial markets, with significant portfolio implications for investors.

Figure 1 graphically illustrates the system-wide connectedness between the clean energy and Australian electricity markets. The dynamic connectedness highlights that spillovers are sensitive to crisis periods and exhibit timevarying attributes, with significant spikes representing periods of economic stress. Accordingly, the troughs in the graph show the return of markets to normal conditions. The initially skewed point in the graph shows the higher connectedness of markets during 2006-2007, a drought period when the Australian electricity markets experienced extreme electricity demands in the hot summer season, causing a peak in the graph (Apergis et al., 2020; Finkele et al., 2006). The drought condition during this initial spike increased electricity consumption and relevant electricity demands in Australia (Apergis et al., 2019). As weather conditions return to normal, the electricity markets tend to normalize, which decreased the connectedness among the markets. Correspondingly, the sharp rise in the graph during 2007-2008 results from the global financial crisis, when the economic downturn caused the clean energy and electricity markets to be highly connected. Similarly, the spike during 2011-2013 indicates the flood situation in QLD (Bohensky \& Leitch, 2014), which drastically affected the system's overall connectedness. The subsequent spike in connectedness indicates the carbon scheme during 2012-2014, which directed power generators to replace dirty energy with clean and renewable energy sources (Do et al., 2020). The spike during 2012-2014 was due to the sudden news of the proposed carbon policy, which generated high spillover and strong connectedness among the markets (Apergis et al., 2017).

At the same time, the large spike in the graph of Figure 1 during 2017 reflects the closure of several coal-fired power

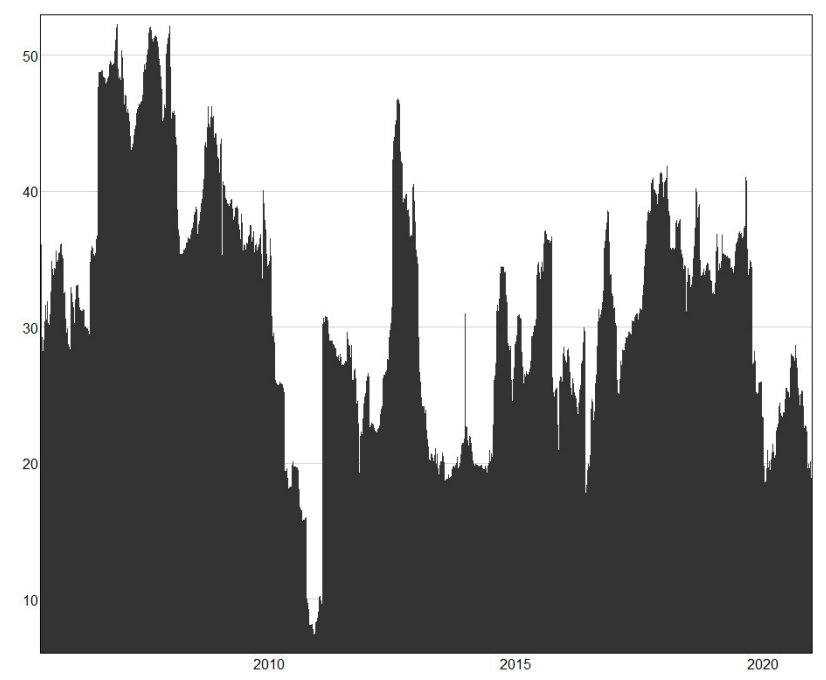

Figure 1. Total connectedness

This figure shows time-varying connectedness.

plants in the Australian electricity markets (Han et al., 2020). Their sudden shutdown increased the connectedness of the markets, consistent with the findings of Apergis et al. (2019). Finally, the last spike in the graph indicates the onset of the recent ongoing COVID-19 pandemic, which resulted in the higher connectedness of the markets. In parallel with the study of Naeem \& Karim (2021), we find that the global COVID-19 pandemic has caused greater connectedness among the markets, exhibiting the global economic shock.

Figure 2 depicts the total net connectedness of the clean energy and Australian electricity markets, reiterating the findings reported in Table 2. As shown in the figure, VIC and NSW are the net contributors of spillovers among the markets, due to their close geographies, high power generation, and maximum alternate sources of energy for generating power (Ignatieva \& Trück, 2016; Manner et al., 2019). On the other hand, TAS, QLD, SA, and SPCL are the net receivers of spillovers. The net recipient attributes of Australian markets suggest that these markets rely on one or two power generation sources and do not generate sufficient power, compared to VIC and NSW (Han et al., 2020). Similarly, SPCL is also a net receiver of spillovers, which aligns with the work of Albulescu et al. (2020), who report 

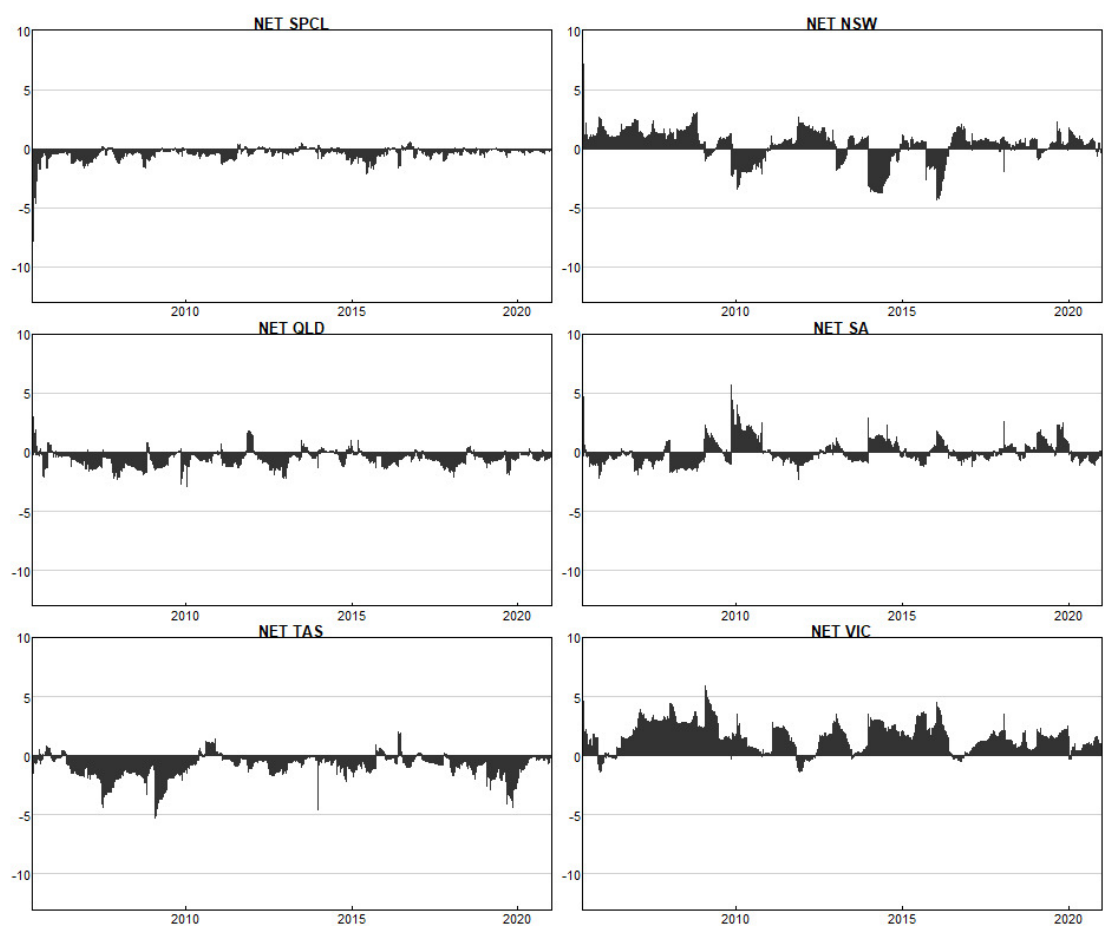

Figure 2. Total NET connectedness

This figure shows time-varying NET connectedness.

weaker connectedness between the clean energy market and other markets.

Figure 3 presents the pairwise connectedness of the clean energy market and the five Australian electricity markets. Interestingly, the spillovers of the clean energy market to the electricity markets are mainly lower, which indicates the diversification potential of the clean energy market for the Australian electricity markets. In line with the study of Liu \& Hamori (2021), the clean energy market provides diversification benefits, implying several recommendations and portfolio management strategies for investors.

\section{Conclusion}

This study examines the connectedness between the clean energy and Australian electricity markets using a TVP-VAR approach from May 2005 to December 2020. We find that VIC and NSW are the net transmitters of spillovers, whereas TAS, QLD, SA, and SPCL are the net recipients of spillovers. The time-varying dynamic analysis confirms the financial contagion impact on system-wide connectedness, with higher connectedness during periods of significant stress. Furthermore, the pairwise connectedness of the clean energy market with other electricity markets demonstrates its diversification potential for Australian markets, with substantial portfolio strategies for investors.

Our findings are important for policymakers, the national electricity market, investors, and financial institutions in terms of using clean energy as an alternate investment tool to take advantage of its diversification potential. Meanwhile, the time-varying connectedness of markets during several periods of stress has implications for in- vestors to rationally consider portfolio diversification strategies in the face of economic, financial, and political uncertainty.

The current research presents future avenues for researchers to include financial markets in the portfolios of energy markets to assess various aspects of their interconnectedness. 

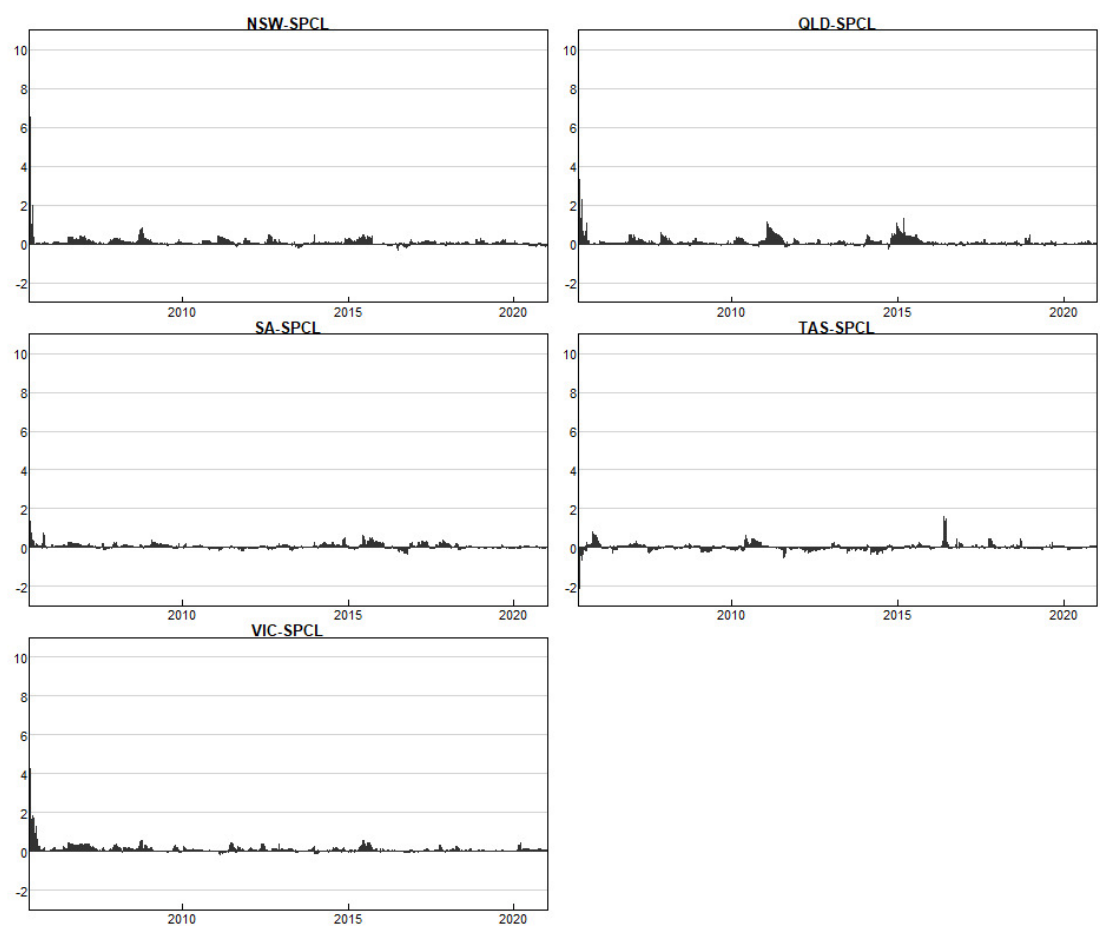

Figure 3. Pairwise connectedness between clean energy and Australian electricity markets

This figure shows pairwise time-varying connectedness of clean energy and Australian Electricity Markets.

This is an open-access article distributed under the terms of the Creative Commons Attribution 4.0 International License (CCBY-SA-4.0). View this license's legal deed at https://creativecommons.org/licenses/by-sa/4.0 and legal code at https://creativecommons.org/licenses/by-sa/4.0/legalcode for more information. 


\section{References}

Albulescu, C. T., Tiwari, A. K., \& Ji, Q. (2020). Copulabased local dependence among energy, agriculture and metal commodities markets. Energy, 202, 117762.

Antonakakis, N., \& Gabauer, D. (2017). Refined Measures of Dynamic Connectedness Based on TVP-VAR [Technical Report]. University Library of Munich.

Apergis, N., Fontini, F., \& Inchauspe, J. (2017). Integration of regional electricity markets in Australia: A price convergence assessment. Energy Economics, 62, 411-418. https://doi.org/10.1016/j.ene c0.2016.06.022

Apergis, N., Gozgor, G., Lau, C. K. M., \& Wang, S. (2019). Decoding the Australian electricity market: New evidence from three-regime hidden semiMarkov model. Energy Economics, 78, 129-142. http s://doi.org/10.1016/j.eneco.2018.10.038

Apergis, N., Gozgor, G., Lau, C. K. M., \& Wang, S. (2020). Dependence structure in the Australian electricity markets: New evidence from regular vine copulae. Energy Economics, 90, 104834. https://doi.or g/10.1016/j.eneco.2020.104834

Bohensky, E. L., \& Leitch, A. M. (2014). Framing the flood: A media analysis of themes of resilience in the 2011 Brisbane flood. Regional Environmental Change, 14(2), 475-488. https://doi.org/10.1007/s10113-013-0 438-2

Do, H., Nepal, R., \& Smyth, R. (2020). Interconnectedness in the Australian National Electricity Market: A Higher-Moment Analysis. Economic Record, 96(315), 450-469. https://doi.org/1 $\underline{0.1111 / 1475-4932.12563}$

Elsayed, A. H., Nasreen, S., \& Tiwari, A. K. (2020). Time-varying co-movements between energy market and global financial markets: Implication for portfolio diversification and hedging strategies. Energy Economics, 90, 104847. https://doi.org/10.101 6/i.eneco.2020.104847

Finkele, K., Mills, G. A., Beard, G., \& Jones, D. A. (2006). National gridded drought factors and comparison of two soil moisture deficit formulations used in prediction of forest fire danger index in Australia. Australian Meteorology Magazine, 55, 183-197.
Han, L., Kordzakhia, N., \& Trück, S. (2020). Volatility spillovers in Australian electricity markets. Energy Economics, 90, 104782. https://doi.org/10.1016/j.enec o.2020.104782

Ignatieva, K., \& Trück, S. (2016). Modeling spot price dependence in Australian electricity markets with applications to risk management. Computers \& Operations Research, 66, 415-433. https://doi.org/1 $\underline{\text { 0.1016/j.cor.2015.07.019 }}$

Li, H. X., Edwards, D. J., Hosseini, M. R., \& Costin, G. P. (2020). A review on renewable energy transition in Australia: An updated depiction. Journal of Cleaner Production, 242, 118475. https://doi.org/10.1016/j.jcle pro.2019.118475

Liu, T., \& Hamori, S. (2021). Does Investor Sentiment Affect Clean Energy Stock? Evidence from TVP-VARBased Connectedness Approach. Energies, 14(12), 3442. https://doi.org/10.3390/en14123442

Manner, H., Fard, F. A., Pourkhanali, A., \& Tafakori, L. (2019). Forecasting the joint distribution of Australian electricity prices using dynamic vine copulae. Energy Economics, 78, 143-164. https://doi.o rg/10.1016/i.eneco.2018.10.034

Musa, S. D., Zhonghua, T., Ibrahim, A. O., \& Habib, M. (2018). China's energy status: A critical look at fossils and renewable options. Renewable \& Sustainable Energy Review, 81, 2281-2290.

Naeem, M. A., \& Karim, S. (2021). Tail dependence between bitcoin and green financial assets. Economics Letters, 208, 110068. https://doi.org/10.1016/j.econle t.2021.110068

Primiceri, G. E. (2005). Time varying structural vector autoregressions and monetary policy. Review of Economic Studies, 72(3), 821-852. https://doi.org/10.1 111/j.1467-937x.2005.00353.x

Taghizadeh-Hesary, F., \& Yoshino, N. (2019). The way to induce private participation in green finance and investment. Finance Research Letters, 31, 98-103. htt ps://doi.org/10.1016/j.frl.2019.04.016

Yan, G., \& Trück, S. (2020). A dynamic network analysis of spot electricity prices in the Australian national electricity market. Energy Economics, 92, 104972. http s://doi.org/10.1016/j.eneco.2020.104972 